\title{
20. COMMISSION DES POSITIONS ET DES MOUVEMENTS DES PETITES PLANETES, DES COMETES ET DES SATELLITES
}

\section{Report of Meetings}

President: P. Herget.

SECRETARY: J. Kovalevsky.

INTERPRETER: S. Arend.

\section{First Meeting, 27 August 1964}

The first session of Commission 20 was opened at $9^{\mathrm{h}} 00^{\mathrm{m}}, 27$ August, by the President with a word of welcome, and a recognition of each of the members present (to indicate who had the privilege to vote). He introduced Dr J. Kovalevsky as Secretary of the Commission for this Assembly, Dr S. Arend as interpreter, and then listed the names of the members of the Organizing Committee. Dr W. Fricke had asked to be relieved of his place on the committee, and the name of Dr Harley Wood was suggested as a replacement, for action at the final session. On the Working Group for Comets, Dr J. G. Porter asked to be relieved as Chairman, and the name of Dr Elizabeth Roemer was suggested for this position. Dr Porter will continue as a member of the Group.

The President recognized Prof. G. A. Chebotarev by extending congratulations to him upon his recent designation as Director of the Institute of Theoretical Astronomy at Leningrad, succeeding Prof. M. Subbotin. The President then conveyed the personal regrets of Miss Roemer in being unable to attend the sessions of this Assembly. The names of new members of the Commission were read: Evdokimov, C. J. van Houten, I. van Houten-Groeneveld, O. Kippes, J. Kovalevsky, Kazimirchak-Polonskaya, Zadunaisky.

During a standing tribute to the memories of the members who had passed away, within the last triennium, the President read the following short résumés:

Professor Antonio Gennaro was born in Modica (Sicily) in 1902; he studied in Pisa and received his doctor's degree in 1925 and immediately became assistant for Mathematics at the University of Pisa. In 1926 , he became assistant at the Trieste Observatory, then at the Latitude Service Station at Carloforte and, finally, astronomer at the Padua Observatory, where he was also lecturer for higher Mechanics and Geodesy. A. Gennaro worked in the field of Astronomy and computed many comet and double star orbits. Recently, he also devoted himself to stellar spectroscopy. He died 30 May 1962, in Padua.

Fernand Rigaux was above all an observer. He began with the observations of variable stars and came soon to the minor planets. His last work was a photographic observation of a solar eclipse in February I96r in Yugoslavia. He devoted a part of his activity to the well known list of astronomers and observatories, which was edited in 1959 by the Royal Observatory of Uccle. He died on 21 September 1962.

Herman S. Spigl, of Perth Observatory, died in August 1962. He had worked successfully for the restoration of active observational work in his observatory. The plans for moving to a site outside the city are now being carried out and commencement of the observations of comets in the southern hemisphere is a contribution to the work of Commission 20.

The agenda for the sessions was announced, and also the selections of the Executive Committee for the coming triennium: Dr Paul Herget, as President; and Dr S. G. Makover, as Vice-President. 
As Director of the Minor Planet Centre at Cincinnati, Dr Herget related that the subsidy provided by the IAU is used only to defray mailing expenses of the MPC's, the cost of the highgrade rag paper on which they are printed, and other expenses incidental to the operations of the Centre. The funds are not used for any salaries. The following financial resolution was proposed and adopted. 'Commission 20 recommends that the Minor Planet Centre at Cincinnati continue to issue the Minor Planet Circulars, and that a sum of $\$ 75^{\circ} \cdot 00$ per annum be made available to the Minor Planet Centre for defraying the necessary expenditure.'

\section{THE DRAFT REPORT}

Several known corrections to the Draft Report were read. The President read a contribution by $\mathrm{Dr} \mathrm{T}$. Gehrels which had inadvertently been omitted. It is printed in the final report, as well as the report from the U.S.S.R. which arrived too late to be included in the printed Draft Report, but some copies of which were available to the members.

\section{OBSERVATIONS}

In so far as future observations are concerned, $\operatorname{Dr} F . K$. Edmondson of the Goethe Link Observatory and $\mathrm{Dr} H$. W. Wood of the Sydney Observatory indicated that they expect to continue observations at the same rate as in the immediate past. $\mathrm{Dr}$ Brouwer indicated that some observations could be undertaken on the new southern astrograph in Argentina. $\mathrm{Dr}$ Missana expressed the opinion that Prof. Cecchini of Torino would resume minor planet observations if the Commission confirmed the need. $M r$ B. M. Millet of the Bordeaux Observatory reported that he has recently taken 200 plates for minor planets, and he proposes to continue such work. Dr Herget remarked that the Cincinnati Observatory is prepared to compute the plate reductions for any observers, provided they supply the measures in a special format which uses dependences.

$\operatorname{Dr} C . \mathcal{F}$. van Houten reported the latest figures for the minor planet survey from plates of the Palomar 48-inch Schmidt. (cf. Transactions IAU, r2 A, pp. 241, 242). There are 895 objects in September and October; 952 objects in September only; and 238 objects in October only, making a total of 2085. (Subsequently, more than I35 objects were transferred to the first category.) Twelve new Trojans were discovered, and seven other objects are suspected of being Trojans. One comet was found. The plate reductions were computed at Cincinnati, and the orbits and search ephemerides were computed on the NORC. Statistical studies at Leiden indicate that the asteroid ring is homogeneous as far as the faint asteroids are concerned; this is in contrast to the results of the previous survey published in the Astrophys. $f$. Suppl.

Dr Herget proposed, in view of the lack of observations of minor planets, to organize an I8-months survey, using the 40-inch, $F \cdot 5$ Baker, distortionless cameras which are already mounted at the centre of each NASA Minitrack station and used for station calibrations. Test plates show that the I6th magnitude should be reached, and a precision of one second of arc is contemplated. Such a survey should give positional results comparable in importance to those obtained from Kuiper's survey in 1950-52. Since this is such a large-scale undertaking, the proposal is not extended beyond 18 months at the present time. The Chairman suggested consideration of a proposal to support this plan.

ORBITS, EPHEMERIDES, IDENTITIES, ETC.

Drs Chebotarev, Herget, and Strobel commented on this phase of the work described in the Transactions $I A U, \mathbf{1 2 A}$. The Institute of Theoretical Astronomy, Leningrad, continues to publish the annual ephemeris volume in an entirely satisfactory manner and has the responsibility for about three-fourths of all the minor planet orbits. More than 200 orbits, computed by 
Cincinnati on the NORC, have all the ephemerides until $2000 \mathrm{AD}$ reduced to microfilm, and copies are on deposit at Leningrad, Heidelberg, and Washington. At Cincinnati the Index of Minor Planet Observations has one punched card for each observation since I939, plus earlier ones when they have been used in an orbit correction. The total now exceeds 80000 . About 40 planets are ready to be numbered on the basis of established identities, as soon as the final computations can be completed, and especially if the objects can be successfully recovered on the basis of the presently-established orbits. The determination of identities continues to be an important source of information, especially from the successful work of Dr O. Kippes. At Heidelberg the handwritten card records of references to observations and orbit calculations extend back to $\mathbf{I} 890$, and all this material has appeared in the successive Heidelberg publications. The records continue to be kept up to date.

Dr Herrick continues his work on a few planets which make a close approach to the Earth. Recently the recovery of $1948 \mathrm{OA}$ was within a few seconds of arc of his ephemeris. He also provides ephemerides for the IXth and XIIth satellites of Jupiter. Dr Kovalevsky will provide ephemerides for the VIIIth satellite. Dr Herget has new programs for the IBM I620 to compute integrations and differential corrections for the outer satellites of Jupiter. The orbit of $\mathrm{J} \mathrm{XI}$ is completed, $\mathrm{J}$ VI is completed from discovery to $\mathrm{I} 9 \mathrm{I2}$, and $\mathrm{J} \mathrm{X}$ is in progress. Dr Rabe is interested in continuing work on the special objects, Eros, Griqua, and Laodamia, all of which have recently been observed by Miss Roemer. Dr $\mathcal{F}$. Schubart provided an ephemeris for the recovery of (122I) Amor, and he will continue this work.

\section{PROPOSALS}

Drs Wilkins and Porter supported the proposal that the publication of solar co-ordinates referred to the beginning of the current year are no longer useful in orbit computations. It was also indicated that there is some basis for confusion, because some quantities are given for the beginning of the current year, and others are to the nearest beginning of the year. Dr Sconzo thought that these data are still important for space research. The Chairman indicated that the U.S. Nautical Almanac Office provides special computations of the rectangular solar and lunar coordinates for space research. By a vote of 20 to 2, the following Resolution was transmitted to Commission 4. 'Commission 20 draws the attention of Commission 4 to the fact that the equatorial rectangular co-ordinates of the Sun referred to the mean equinox of the beginning of the current year are no longer required for orbit computations.'

The Chairman asked Dr Protitch to speak in support of his proposal, so that it could be carefully considered before the final session. Dr Protitch felt that he and other small observatories face two difficulties. The observers would have more time for observing if they could be relieved of the task of computing plate reductions. Therefore, he proposes that an international computing bureau be set up for such work. Secondly, there is great difficulty in securing high quality plates in small quantities. It seems that the producers require large quantity orders, and then the plates deteriorate before they can be used. Hopefully some international co-operation could ameliorate this problem amongst smaller observatories.

\section{Session on Comets}

Chairman: Dr J. G. Porter.

The Chairman expressed his regret at the absence of Miss Elizabeth Roemer, currently the most active comet observer. He commented on several aspects of the report of the Working Group. Dr Kresák's proposal recognizes the difficulty which sometimes exists in collecting all the observations of a comet when an orbit improvement is undertaken. Dr Herget proposed to undertake at the Minor Planet Centre at Cincinnati the maintainance of a punched-card 
repository of all comet observations, in much the same fashion as the Index of Minor Planet Observations is now kept. Printed lists or duplicate punched cards of all the observations of any comet would be supplied upon request.

Dr Zadunaisky gave a short account of his current work on Halley's Comet. He has used 2800 observations from the return of I910, collected and reduced by Bobone, he applied the correction for ephemeris time, computed the perturbations of all the planets, and computed two orbits. The first is fitted to all the observations before the perihelion passage, and the second to all those following the perihelion passage. The two orbits do not match each other. Dr Zadunaisky now proposes to use the observations from 1835 .

Dr Porter summarized the two main conclusions of the report. (1) No orbit should be published without the residuals. (2) The duplication of orbit computations is not something to be avoided, but to be encouraged. As an example, he cited the recent experience with Comet d'Arrest. Miss Roemer had taken 29 plates and failed to recover the comet. Then Marsden hurriedly completed computations of his own, and the object was located on the first night. $\mathrm{Mr}$ Marsden remarked that his orbit differed by 8 days in the time of perihelion passage, but even a plate from the Palomar 48 -inch Schmidt would not encompass such a large difference. His numerical integration programme takes into account the outer planets at a ro-day interval, and the inner planets are represented by a Keplerian ellipse. Dr Porter noted that the most precise computations for comets were still made by hand, namely Kamienski on Comet Wolf I and Repinski on Comet Kopff.

\section{PROPOSALS: (IAU TRANSACTIONS, I $2 A$, PAGE 240)}

(I) After discussions by Herget, Hertz, Marsden, and Zadunaisky, it appears that, with electronic computers, there is no advantage in the use of normal places; in fact, some information can be lost in such a procedure.

(2) The problem of an international computing centre falls outside the scope of this Commission. The proposal has been made several times, but it never materializes because the investigators wish to do their own computing.

(3) This is covered by Dr Herget's above proposal, but further discussion clarified two points. (a) The existence of the Repository would in no way restrict the correspondence between the observer and the computer during the time immediately after discovery. (b) The Cincinnati Observatory would not aggressively seek to collect the comet observations, but would simply maintain the file of all those which are sent in.

The President again presided and called for a vote on the membership of the Working Group on Comets for the coming triennium. Those elected were Candy, Kepinski, Kresák, Makover, Porter, and Miss Roemer as Chairman. The Draft Report was then formally adopted by the Commission, and the session adjourned.

\section{Second Meeting, $3^{1}$ August 964}

The President called the session to order at $9^{\mathrm{h}} \mathrm{oo}^{\mathrm{m}}$. The Organizing Committee for the coming triennium was formally approved: S. Arend, D. Brouwer, F. K. Edmondson, H. Hirose, H. Wood.

Dr Herget announced that, since the Minor Planet Circulars are subsidized by the IAU, they are sent free of charge to all recognized astronomical observatories, astronomical libraries, and active research workers in this field. In the future, other requests will be accepted whenever there is an advance payment made of $\$ 25.00$ per 1000 MPC numbers. 
PROPOSALS

The Commission adopted the following Resolutions, each by a formal vote.

(I) 'Commission 20 recommends that the Institute of Theoretical Astronomy modify the printed list of elements in the annual ephemeris volume by removing the " $S$ " for special perturbations, retaining the " $A$ " for absolute perturbations, and introducing " $E$ " for elliptic elements when there are no perturbations.'

(2) 'Commission 20 recommends that the Minor Planet Centre publish in the Minor Planet Circulars a list of those minor planets which need to be observed in the immediate future in order that the solution for the improvement of their elements will be strengthened appreciably. Contributions to this list shall be submitted by those engaged in the correction of elements.'

(3) 'Commission 20 recognizes as one of the most serious problems in its area of interest the continual diminution of the number of observations of minor planets. Therefore the Commission welcomes the project proposed by Dr Paul Herget to photograph an ecliptic band of the sky by means of the calibration cameras of the NASA Minitrack stations, and to blink, measure, and reduce all the minor planet positions so obtained. The Commission recommends that strong support be given to this project from all possible sources.'

(4) 'Commission 20 reaffirms the importance of continuing the programme of minor planet observations at the Goethe Link Observatory (Indiana University, U.S.A.), and hopes that adequate financial support will be continued in the future.'

(5) 'In consideration of the diminution of the number of observations of the minor planets, the Commission recommends that the Observatory of Pino Torinese again undertake the observations of minor planets.'

(6) 'In consideration of the diminution of the number of observations of the minor planets, the Commission recommends that the Astrophysical Observatory of Shemakha again undertake the observations of minor planets.'

(7) 'Commission 20 recommends that the Minor Planet Centre at Cincinnati be asked to form an Index of Positions of Comets on punched cards, similar to that already existing for minor planets; and that, in order for the Index to be of maximum value, observers should send all of their measured positions of comets, whether published or not, to the Centre. It is agreed that information from this Index will be supplied upon request.'

In the discussion concerning (3) above, $\mathrm{Dr}$ Arend expressed the opinion that an accuracy of only about 3 seconds of arc could be attained and therefore that these positions should receive a designation to distinguish them from others taken with longer-focus astrographs. Drs Missana and Kovalevsky mentioned that small instruments in Asiago and Meudon showed the possibility of attaining an accuracy of I second of arc. In these cases, the limitation is instrumental, whereas with the long-focus telescopes it is probably due to the star catalogues. Dr Herget pointed out that in any event all the observations are used in an orbit determination, and their residuals reveal their relative accuracy and appropriate weights. He indicated, in reply to a question by $\mathrm{Dr} H e r t z$, that the initial proposal for the survey did not contemplate dealing with newly discovered objects.

Concerning the proposal of Dr Protitch, Dr Herget reiterated the offer of the existing, co-operative plan of the Cincinnati Observatory to compute plate reductions for observers, and suggested that this be carried out by individual agreements with the observers.

The President then presented a topic introduced by the European Space Research Organization (ESRO), concerning the uncertainties which would be involved in the ephemerides of certain periodic comets, in the case of a contemplated rendezvous of a space vehicle with the comet. Dr P. Stumpff indicated that an actual approach of $10000 \mathrm{~km}$ to the nucleus would 
be desirable. Drs Porter and Rabe described some experience with such studies; additional difficulties lie in the area of organizing the use of recovery observations to provide the most reliable current predictions. To crystallize the response of the Commission to ESRO, it was voted to establish a Working Group consisting of Drs Herrick, Rabe, Roemer, and Dr Porter as chairman. A report should be submitted by March 1965 .

Dr Wilkins reported on the progress of his work on the satellites of Mars. Observations from I 877 to 1929 have been rediscussed. No secular acceleration was found in separate solutions for each satellite. Relative observations of 1941 and $195^{6}$ will be taken into account in the next part of the work.

Dr Zadunaisky intends to recompute the orbit of Phoebe, ninth satellite of Saturn. A basic

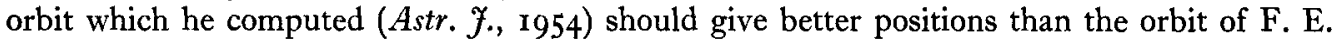
Ross (Annals of the Harvard Observatory, 1905), which is currently being used for the published ephemerides. Additional observations have become available in recent years, and these will strengthen a definitive determination of the motion.

The President thanked all the participants of these sessions, and declared the meetings of this Commission adjourned. 